\title{
Research waste related editorial policies of leading dental journals: Situation 2018
}

DOI:

10.1111/odi.13257

\section{Document Version}

Accepted author manuscript

Link to publication record in Manchester Research Explorer

\section{Citation for published version (APA):}

Almaqrami, B. S., Hua, F., Liu, Y., \& He, H. (2019). Research waste related editorial policies of leading dental journals: Situation 2018. Oral Diseases. https://doi.org/10.1111/odi.13257

\section{Published in: \\ Oral Diseases}

\section{Citing this paper}

Please note that where the full-text provided on Manchester Research Explorer is the Author Accepted Manuscript or Proof version this may differ from the final Published version. If citing, it is advised that you check and use the publisher's definitive version.

\section{General rights}

Copyright and moral rights for the publications made accessible in the Research Explorer are retained by the authors and/or other copyright owners and it is a condition of accessing publications that users recognise and abide by the legal requirements associated with these rights.

\section{Takedown policy}

If you believe that this document breaches copyright please refer to the University of Manchester's Takedown Procedures [http://man.ac.uk/04Y6Bo] or contact uml.scholarlycommunications@manchester.ac.uk providing relevant details, so we can investigate your claim.

\section{OPEN ACCESS}




\section{Research waste related editorial policies of leading dental journals: Situation 2018}

Running title: Research waste related to dental journals

Bushra Sufyan Almaqrami 1,+; Fang Hua 1,2,3,+; Yanxiaoxue Liu1 ;Hong He 1,*

1. Department of Orthodontics, Hubei-MOST KLOS \& KLOBM, School \& Hospital of Stomatology, Wuhan University, Wuhan, China.

2. Centre for Evidence-Based Stomatology, Hubei-MOST KLOS \& KLOBM, School \& Hospital of Stomatology, Wuhan University, Wuhan, China

3. Division of Dentistry, School of Medical Sciences, Faculty of Biology, Medicine and Health, University of Manchester, Manchester Academic Health Science Centre, Manchester, UK.

+ These authors contributed equally to this work and should be regarded as joint first authors.

*orresponding author:

Hong He, Department of Orthodontics, Hubei-MOST KLOS and KLOBM, School \& Hospital of Stomatology, Wuhan University, Luoyu Road 237, Hongshan District, Wuhan 430079, China (E-mail: drhehong@whu.edu.cn)

Keywords: avoidable research waste, reporting guideline, open access, data sharing. 


\title{
Research Waste Related Editorial Policies of Leading Dental Journals: Situation 2018
}

\begin{abstract}
Objectives: To study whether specific recommendations aimed at reducing avoidable research waste were included in the author instructions of leading dental journals.

Method: We identified 109 peer-reviewed and original research-oriented dental journals that were indexed in the MEDLINE and/or SCIE database in 2018. Two authors extracted independently information regarding the endorsement of reporting guidelines (RGs), ICMJE recommendations, trial or systematic review registration, as well as open access (OA) and data sharing policies.

Result: All 109 journals provided online "instructions to authors", among which 64 journals (58.7\%) mentioned RGs. The ICMJE recommendations were endorsed by 74 journals $(67.9 \%)$, trial and systematic review registration were mentioned by $48(44.0 \%)$ and $6(5.5 \%)$ of the journals, respectively. In terms of open access, most journals stated they were Hybrid OA (82.0 $\%$ ), Direct OA (15.4\%); while data sharing policy was recommended by 32 (29.4\%) journals. Statistical analyses suggest that these policies were more frequently mentioned by SCIE-indexed journals, higher-impact journals, and journals that endorsed the ICMJE recommendations.

Conclusion: Adequate reporting, $\mathrm{OA}$ and data sharing are important tools for enhancing research communication, translation and the reduction of avoidable research waste. However, currently they are not widely endorsed by dental journals.
\end{abstract}

\section{Introduction}

Biomedical research expends approximately a quarter of trillion US dollars yearly. Evidence suggests that a great extent of this sum is being avoidably wasted (Moher et al., 2016). Publications from 2009, 2014 and 2016 in The Lancet have primarily attributed this waste to imbalanced research questions, insufficient registration of clinical trials, failure of new research to systematically review previous findings in the same topic area, flawed study design and execution, nonpublication and lack of accessibility and sharing. These problems have led to an avoidable waste of $85 \%$ of all research funds in biomedicine, implying a global total loss of over US\$100 billion per year (Chalmers et al., 2014; Chalmers \& Glasziou, 2009; Ioannidis, 2008; Moher et al., 2016).

Waste in research could be avoided if all studies are preceded by systematic assessment of existing evidence (Lund, Juhl, \& Christensen, 2016). Systematic reviews often identify gaps in 
the evidence base and provide a decision about whether and what additional primary research should be conducted (Egger \& Smith, 1997; Glasziou P., 2015). Nevertheless, evidence indicates that researchers (Clarke \& Chalmers, 1998; Clarke, Hopewell, \& Chalmers, 2007; Glasziou P., 2015; Habre, Tramer, Popping, \& Elia, 2014; Robinson \& Goodman, 2011; Sawin \& Robinson, 2016) and even high-quality clinical studies (Clarke \& Chalmers, 1998; Clarke et al., 2007; Habre et al., 2014; Robinson \& Goodman, 2011) published in most important medical journals often fail to use previous research findings when preparing, designing or discussing new research. Under citation of earlier research is a particularly problematic issue when the selection of earlier studies is biased (Gotzsche, 1987). An investigation of clinical trials performed over four decades revealed that, irrespective of the number of relevant previous trials, less than a quarter of previous studies have been cited in reports (Robinson \& Goodman, 2011).

The prospective registration of protocols for clinical trials and systematic reviews is becoming a valuable tool for investigating what is already being researched (Booth et al., 2011). The prospective registration of clinical trials represents a key factor in reducing waste in research (Ioannidis et al., 2014) because it eliminates redundancy by distinguishing and therefore preventing unnecessary duplication of research and publications. However, only less than one-quarter of RCTs with results published in a sample of oral health journals (Smail-Faugeron, Fron-Chabouis, \& Durieux, 2015) or general and specialty medicine studies (Wager \& Williams, 2013) were registered with a public registry.

The active execution of reporting guidelines (RGs) for reporting different kinds of studies is one method that journals can utilise to help reduce waste due to poor reporting (Hopewell, Ravaud, Baron, \& Boutron, 2012; Pandis, Shamseer, Kokich, Fleming, \& Moher, 2014; Turner et al., 2012). During the last two decades, journal editors and methodologists have developed and published numerous RGs in an attempt to enhance research reporting and thereby facilitate critical appraisal and their inclusion in meta-research. In addition, the Enhancing the Quality and Transparency of Health Research (EQUATOR) network has worked since 2008 to enhance the reliability and value of medical research publications through the advancement of transparent and appropriate reporting (Simera et al., 2010). Unless research is properly reported, the time and resources invested in its conduct are wasted.

The development of open access (OA) (Joseph, 2013) is also an important and suggested method for reducing avoidable waste in biomedical research (Chalmers \& Glasziou, 2009). OA may enrich education, accelerate research and provide advantages to all stakeholders, including 
researchers and practitioners, particularly those in resource-poor institutions and low-income countries (Clauson, Veronin, Khanfar, \& Lou, 2008; Giglia, 2010). The appreciation of 85\% of research waste refers only to activities prior to the point of publication. However, considerable waste occurs after publication due to poor access, poor dissemination and poor research finding uptake (Glasziou, 2014). The main beneficiaries of dental and medical research include not only researchers but also clinicians, patients and policy-makers who usually have limited access to full articles behind the pay wall (Kurata, Morioka, Yokoi, \& Matsubayashi, 2013; Moorhead, Holzmeyer, Maggio, Steinberg, \& Willinsky, 2015). Therefore, development of OA in research (Joseph, 2013) is important for reducing post publication waste. Solving the problems of prepublication waste and post publication access could considerably accelerate medical research.

Sharing research data has attracted increasing interest because associating large healthcare datasets allow enriching data on symptoms, diagnoses diseases, treatments and prescriptions, in addition to providing increased effectual semantic access to the evidence base (Kostkova et al., 2016). Data sharing could reduce research waste by enabling new types of research. For example, meta-analyses using individual patient data from published clinical trials have revealed numerous novel findings that go well beyond the limitations of original studies that generated the data (Fournier et al., 2010). Policies directing researchers to share data in biomedical research are also becoming commonplace (Wellcome Trust, 2016).

In 2014, The Lancet published a series of five reviews (Al-Shahi Salman et al., 2014; Chalmers et al., 2014; Chan et al., 2014; Glasziou et al., 2014; Ioannidis et al., 2014) showing ways to minimise waste and increase value in biomedical research. Seventeen recommendations were provided to five key stakeholders of medical research, namely, academic institutions, journals, regulators, funders, and researchers. Journals are recommended to improve their editorial policies and provide specific guidance to researchers through their content and websites. In 2015, Moher et al. (Moher et al., 2016) investigated the editorial policies of leading medical journals by focusing on 10 core questions that are related to research waste. A survey of dental journal editors conducted by Hua et al. (Hua, Walsh, Glenny, \& Worthington, 2016) in 2016 provided thorough information regarding the use of RGs in dentistry. Hence, to our knowledge, whether and to what extent dental journals have adopted editorial policies that can reduce avoidable research waste remains unclear. Therefore, the objectives of this methodological study were to investigate the current usage of research waste-related policies by leading dental journals and to explore factors associated with such usage. 


\section{Materials and Methods}

\subsection{Sample Creation}

\subsubsection{Selection of Journals}

We set out to include all main dental journals (indexed in MEDLINE and/or SCIE) that were active, peer reviewed and original research oriented.

\subsubsection{Selection of RGs and ICMJE Recommendations}

A list of main RGs and ICMJE recommendations relevant to dental research was developed a priori to ensure the comprehensiveness and relevance of this study. In November 2018, the authors recognised main and potentially relevant RGs and ICMJE recommendations by screening them in the online RG library of the EQUATOR Network and ICMJE. Discrepancies were resolved by discussion. Twenty-three RGs or RG extensions and two items of the ICMJE Recommendations were included (Tables 1 and 2)

\subsubsection{Survey of Journal Instructions}

For each of included journal, an electronic search was conducted from November 29 to December 2, 2018 to identify any 'instructions to authors'.

From each of the obtained instructions, the following predetermined information (Moher et al., 2016) was extracted by B.A. and independently verified by Y.L.:

- Does the instruction explicitly mention RGs and/or the EQUATOR Network? If mentioned, what are the endorsement level and the reference given?

- Does the instruction mention the registration of clinical trials or systematic reviews?

- Does the instruction mention the use of systematic reviews as part of the research context?

- Does the instruction mention ICMJE recommendation?

- Does the journal mention any policy related to OA?

- Does the journal include any policy on public access to data from published research?

The endorsement of mentioned RGs and related policies was categorised as follows (Knuppel, Metz, Meerpohl, \& Strech, 2013; Meerpohl, Wolff, Antes, \& von Elm, 2011; Meerpohl, Wolff, Niemeyer, Antes, \& von Elm, 2010):

- Recommended: The RG/policy should be considered or used (e.g. 'should...,' 'please...,' 'we recommend/ encourage authors/reviewers to...').

- Required: The RG/policy is a condition for publication (e.g. 'authors must...,' 'authors are required to...,' 'we expect authors to...').

Regarding the trial registration policy, each journal was categorised into one of two predetermined groups: 1) journals requiring or recommending trial registration (as a precondition for publication in the context of general manuscript preparation) and 2) journals providing no reference to trial registration (Smail-Faugeron et al., 2015).

OA policies (Hua, Shen, Walsh, Glenny, \& Worthington, 2017) were categorised into three 
types a priori:

1) Direct OA: Journals that were fully OA and without any embargo.

2) Hybrid OA: Journals that were subscription-based and that offered researchers the option to publish their work as Gold OA (Gold OA is broadly defined as providing OA articles through journals or publishers) if they paid a specified publication fee 'hybrid journals.'

3) Green only: Journals that did not provide an option for Gold OA but allowed the authors to make their work OA via self-archiving (Green OA).

When the journal's instructions to the author did not contain any information about OA, policy was documented in accordance with the Sherpa Romeo website. When the journal's instructions to authors contained policy but was inconsistent with the Sherpa Romeo website, policy was documented in accordance with instructions that were more recently updated than the Sherpa Romeo website.

Data-sharing policy was categorised into 1) Recommended: The data-sharing policy should be considered or used (e.g. 'should...,' 'please...,' 'we recommend/encourage authors/reviewers to...'). 2) Required: The data-sharing policy is a condition for publication (e.g. 'authors must...,' 'authors are mandating to...,' 'we expect authors to...').

\subsection{Statistical Analyses}

For the journal instruction survey, descriptive statistics were used to summarise the endorsement of each policy. Chi-square test was used to test the significance of differences amongst the types of dental journals as either general or specialty; amongst the specific subject of dental journal; whether the dental journal was indexed in SCIE or not; whether the journal had an impact factor or not; whether journals had an OA policy or not and whether the journal endorsed the ICMJE recommendation or not. Data were entered and analysed using the statistical package for social services Version 24 (Armonk, NY: IBM Corp.) for Windows software.

\section{Results}

\subsection{Characteristics of Included Journals}

A total of 169 unique journals were initially identified in the electronic databases, with 109 remaining after the implementation of eligibility criteria (Figure 1). The titles of the journals and the summary of the characteristics of the journals are shown in (Tables 3 and 4).

\subsection{Instructions to Authors}

All journals $(n=109)$ included in our study provided online instructions for authors. Amongst the Twenty-three RGs that were deemed important for dental research, nine were never mentioned (Table 5).

\subsubsection{Endorsement of $R G S$}

A total of 64 journals (58.7\%) mentioned RGs (Figure 2). The guidelines were mentioned in Consolidated Standards of Reporting Trials (CONSORT, 49.6\%), Preferred Reporting Items for Systematic Reviews and Meta-analyses (PRISMA, 27.5\%), Animal Research: Reporting of In 
Vivo Experiments (23.9\%) and Strengthening the Reporting of Observational Studies in Epidemiology (STROBE, 20.2\%; Table 5). In addition to the 23 prespecified RGs, seven journals (6.4\%) mentioned relevant Cochrane Collaboration guidelines as RGs for systematic reviews; three journals mentioned the Minimum Information about a Microarray Experiment guideline (MIAME); one journal mentioned the Transparent Reporting for Individual Prognosis or Diagnosis guideline (TRIPOD); and one journal mentioned the Consolidated Health Economic Evaluation Reporting Standards guideline (CHEERS). Notably, the Quality of Reporting of Meta-analyses guideline (QUOROM), an obsolete guideline replaced by PRISMA in 2009, was still endorsed by five journals (4.5\%). RGs were frequently mentioned by journals indexed in SCI $(\mathrm{P}=0.095)$, journals with OA $(\mathrm{P}<0.001)$, journals with high impact factors $(\mathrm{P}=$ $0.026)$ and journals that endorsed ICMJE recommendations $(\mathrm{P}<0.001)$ (Table 6).

\subsubsection{Mentions of Online RG Libraries}

Seventeen $(15.6 \%)$ and three $(2.8 \%)$ journals mentioned the EQUATOR Network and Minimum Information for Biological and Biomedical Investigations (MIBBI) websites, respectively. Amongst the 17 journals that mentioned the EQUATOR Network, 10 provided the website URL as reference (Table 7).

\subsubsection{Endorsement of the Registration Policy}

Overall, $48(44.0 \%)$ journals referred to trial registration (Figure 2) as either 32 required $(66.7 \%)$ or 16 recommended $(33.3 \%)$ trial registrations, and $61(56.0 \%)$ provided no reference to trial registration (Table 8). Journals indexed in SCI $(\mathrm{P}=0.015)$, journals with high impact factors $(\mathrm{P}=0.007)$, journals with $\mathrm{OA}(\mathrm{P}<0.001)$ and journals that endorsed ICMJE recommendations $(\mathrm{P}<0.001)$ (Table 6) were likely to require or recommend trial registration. However, the prospective registration of systematic reviews was mentioned only by six (5.5\%) of all journals.

\subsubsection{Endorsement of ICMJE Recommendations}

Seventy-four journals (67.9\%) mentioned ICMJE recommendations (Figure 2). Amongst these journals, 32 (43.2\%) used the title Uniform Requirements for Manuscripts Submitted to Biomedical Journals (URM), which is out of date and thus inappropriate; $10(13.5 \%)$ referred to the content of the manuscript preparation section of the ICMJE recommendations; and 18 (16.5\%) referred to the trial registration (Table 9). ICMJE was frequently mentioned by journals indexed in SCI $(\mathrm{P}=0.069)$, journals with $\mathrm{OA}(\mathrm{P}=0.027)$ and journals with high impact factors $(\mathrm{P}=0.109$, Table 6).

\subsubsection{Endorsement of $O A$}

Three policies were identified regarding OA publishing. Firstly, 31 (28.4\%) journals (Figure 2) did not offer any form of OA publishing to researchers in their instructions to the author and in the supplementary website of Sherpa Romeo (www.sherpa.ac.uk). Secondly, 64 (82.0\%) subscription-based journals offered researchers the option to publish their work as OA if they paid a specified publication fee. Such journals were often termed 'hybrid OA.' Thirdly, 12 $(15.4 \%)$ journals were 'direct OA.' Lastly, two (2.6\%) journals allowed the authors to make 
their work OA via self-archiving and were considered 'green OA.' Therefore, 78 journals $(71.6 \%)$ offered some form of OA option (Table 10). The median article processing fees of these journals were $\$ 2355$. OA was frequently mentioned by journals indexed in SCI (P < 0.001), journals with high impact factors $(\mathrm{P}<0.001)$ and journals that endorsed ICMJE recommendations $(\mathrm{P}=0.006)$ (Table 6).

\subsubsection{Endorsement of data sharing.}

Thirty-two (29.4\%) journals mentioned their research data policy (Figure 2), and half of them (14.7\%) referred to Mendeley as the database for data sharing. A total of 30 journals (93.8\%) recommended research data policy, whereas two journals $(6.2 \%)$ requested data sharing in their author instructions. However, only 17 journals $(53.1 \%)$ provided the corresponding website URL as reference (Table 11). Data-sharing policy was frequently mentioned by journals indexed in SCI $(\mathrm{P}=0.156)$, journals with high impact factors $(\mathrm{P}=0.275)$, journals with $\mathrm{OA}(\mathrm{P}<$ 0.001) and journals that endorsed ICMJE recommendations $(P=0.017)$ (Table 6).

\section{Discussion}

The ultimate goal of dental research is to discover and disseminate novel high-quality data to the community. However, some studies published in dentistry journals are often compromised by either incomplete reporting (Papageorgiou \& Cobourne, 2018), and access to research reports is restricted even when studies are adequately reported. To address these issues, efforts are needed to improve all stages of research production and dissemination from the conception of research questions to the full and accessible publication of research findings.

\subsection{RGs and ICMJE recommendations}

Although the adoption of RGs, such as CONSORT, PRISMA and STARD, has helped improve the quality of research reports, substantial gaps remain (Glasziou et al., 2014). This study found low endorsement rates of RGs (58.7\%, particularly for those other than CONSORT) in the instructions to authors of dental journals. However, our results revealed progress in the endorsement of RGs. By contrast, a 2015 survey (Hua et al., 2016) of journal instructions to authors showed that references or recommendations for the use of RGs during reviews was low (55 [50.5\%] of 109 journals assessed).

ICMJE provides recommendations to review best practices and ethical standards in the conduct and reporting of research and other materials published in medical journals. However, the authority to monitor or enforce these recommendations does not exist. Therefore, ethical recommendations should be used in conjunction with journal's instructions for authors (ICMJE, 2018).

This study emphasised several important issues with regard to the ethical policies recommended by ICMJE. A total of 74 journals (67.9\%) mentioned ICMJE recommendations. Amongst these journals, 32 (43.2\%) used the title URM, and 10 (13.5\%) referred to the content of the manuscript preparation section of ICMJE recommendations. Our study demonstrates progress in the endorsement of ICMJE recommendations compared with another study wherein researchers used a methodology similar to that used here. The previous study analysed 109 leading dental journals, and the authors reported that ICMJE recommendations were mentioned by $65(59.6 \%)$ of dental journals (Hua et al., 2016). 


\subsection{Trial and Systematic Registration}

The International Prospective Register of Systematic Reviews was launched in February 2011 (Booth et al., 2012). The prospective registration of protocols for clinical trials and systematic reviews is becoming increasingly available. This tool can help assess what is already being researched (Booth et al., 2011), minimise the unplanned duplication of reviews and serve to discourage bias in the conduct and reporting of systematic reviews. The level of compliance and endorsement with trial and systematic review registration varied and was generally low in dental journals (De Angelis et al., 2004). Our study found that $44.0 \%$ and $5.5 \%$ of the selected dental journals required or recommended trial and systematic review registration, respectively, in their author guidelines. Our results are in agreement with those of previous studies on oral health journals (Smail-Faugeron et al., 2015) and to those on general or specialty medicine studies (Wager \& Williams, 2013).

\subsection{Systematic Contexts}

When decisions about additional primary research are made, research funders and regulators should request that proposals for additional primary research be advocated by systematic reviews of what is already known and increase funding for the necessary syntheses of existing evidence (Health., 2001). Such demands will be effective in setting research priorities and address the sources of avoidable waste. In addition, the existence of previous research must be estimated to avoid unnecessary duplication. The reasonable updating of an existing systematic review with the results of the latest primary study may be justified in confirming previous results or to assess the generalizability of novel findings (Ioannidis, 2014). Nevertheless, unnecessary duplication is usually associated with waste (Chalmers \& Glasziou, 2009). Replications become unnecessary duplication either when systematic reviewers are unconscious of what their colleagues are planning or in the presence of pressure to publish for career progression. Consequently, in recent years, the increased drive for the international endorsement of the register by funders and journals (Davies, 2012), published research protocols, OA publication and improved training for peer reviewers may help reviewers examine identified protocols and reduce unnecessary duplication. When research findings are reported, they should be set in the context of previous analyses or similar research. Some journals are starting to require this information when prospective authors submit the results of their research (Kleinert, Benham, Collingridge, Summerskill, \& Horton, 2014). According to a recent study (Moher et al., 2016), several medical journals have endorsed this policy in their instructions to author, whereas no dental journal has done this. If dental journals follow this behaviour, then the value of scientific research will increase, and waste that originates from seeking to answer research questions that had been answered reliably by previous conducted research would be avoided.

\subsection{OA and Data Sharing}

This study highlights the development of OA publication in leading dental journals with the vast majority $(71.6 \%)$ of journals studied offering authors an OA option. These journals included hybrid OA $(82.0 \%)$, direct OA (15.4\%) and green OA (2.6\%). Interestingly, more than half of the journals included in our study support the gold OA (hybrid OA and direct OA), which has the best accessibility for reducing research waste because early availability and dissemination may improve the time relevance of articles, accelerate the progress of research and benefit all direct and indirect users of research (e.g. patients) (Giglia, 2010; Livas, Pandis, \& Ren, 2015). 
Common and prompt data sharing decreases the unnecessary duplication of research and reduces the waste of resources (Pham-Kanter, Zinner, \& Campbell, 2014). Research funders (Council, 2016) and biomedical journals (Groves, 2010; Nature.com) try to impede the desire to hide data by adopting policies that mandate data sharing. One step in encouraging data sharing in dentistry is to know how many journals promote and accept data affiliated with manuscripts and how datasets are deposited. In this study, we found low endorsement rates (29.4\%) of data-sharing policies, and $68.8 \%$ of these journals had a statement about data availability. These percentages are similar to those found in previous studies that analysed the public availability of research published in the Library and Information Science Journals (Aleixandre-Benavent R, 2016) and in the Substance Abuse Data Journals (Aleixandre-Benavent et al., 2014). Another study found that $88 \%$ of high-impact journals (Alsheikh-Ali, Qureshi, Al-Mallah, \& Ioannidis, 2011) had a declaration in their instructions to authors related to the public availability and sharing of data.

The findings of our study regarding the positive association between the mentioning of these policies and SCIE-indexed journals, high-impact journals, OA journals and journals that endorsed ICMJE recommendations are similar to those of previous studies (Hua et al., 2016; Piwowar \& Chapman, 2008).

Continuing efforts to engage research in wasteful behaviour are serious threats to science worldwide. Findings from a 2009 study proposed that at least $50 \%$ of research reports were poorly reported and therefore unusable (Chalmers \& Glasziou, 2009). Estimating the general losses in research reporting revealed that approximately $50 \%$ loss at this stage would result in loss of more than $85 \%$, implying that the dividends from tens of billions of dollars of investment in research are lost every year because of correctable problems. The research waste of $85 \%$ refers only to activities prior to the point of publication. Additional waste occurs after publication due to poor access, poor dissemination and poor uptake research finding. This waste can also lead to redundant, misguided or potentially harmful research when assessing similar interventions.

\subsection{Strengths and Limitations}

To our knowledge, this study is the first to assess policies related to the research waste of studies published in leading dental journals and to explore factors associated with usage. Given that our sample incorporated journals that were indexed in MEDLINE but not in SCIE, our sample was already more comprehensive than those of previous studies on editorial policies in dentistry (Faggion, 2011; Smail-Faugeron et al., 2015) and other medical specialties (Knuppel et al., 2013; Kunath F, 2012; Meerpohl et al., 2010).

Despite these strengths, the limitation of our study is that the initial observations were partly based on checking websites that were often difficult to handle. Likewise, we could have missed information or some of the content that might have been changed since our investigation. For example, on some journal websites, instructions to authors are modified at the beginning of the calendar year. Therefore, cautious interpretation is needed.

\section{Conclusions}

The results of this study indicate the following:

1) Although the development and application of registration, RGs, OA and data-sharing policies have resulted in some progress in biomedical research, these policies are not widely endorsed 
by dental journals.

2) All stages of production and dissemination in medical research avoidable waste. Dental research can be improved, and waste in dental and medical research can be minimised by adopting editorial policies that provide an accessible, unbiased and comprehensive evidence pool to all stakeholders.

3) Behavioural changes from researchers, publishers and regulators will be needed to maximise waste reduction in research.

\section{References}

Al-Shahi Salman, R., Beller, E., Kagan, J., Hemminki, E., Phillips, R. S., Savulescu, J., . . . Chalmers, I. (2014). Increasing value and reducing waste in biomedical research regulation and management. Lancet, 383(9912), 176-185. doi:10.1016/s0140-6736(13)62297-7

Aleixandre-Benavent R, M.-S. L., Ferrer Sapena A, Pérez EAS (2016). Correlation between impact factor and public availability of published research data in Information Science and Library Science journals. Scientometrics, 107:1-13. doi:10.1007/ s11192-016-1868-7].

Aleixandre-Benavent, R., Vidal-Infer, A., Alonso Arroyo, A., Valderrama Zurian, J. C., Bueno Canigral, F., \& Ferrer Sapena, A. (2014). Public availability of published research data in substance abuse journals. Int J Drug Policy, 25(6), 1143-1146. doi:10.1016/j.drugpo.2014.07.007

Alsheikh-Ali, A. A., Qureshi, W., Al-Mallah, M. H., \& Ioannidis, J. P. (2011). Public availability of published research data in high-impact journals. PLoS One, 6(9), e24357. doi:10.1371/journal.pone.0024357

Beller, E. M., Glasziou, P. P., Altman, D. G., Hopewell, S., Bastian, H., Chalmers, I., ... Tovey, D. (2013). PRISMA for Abstracts: reporting systematic reviews in journal and conference abstracts. PLoS Med, 10(4), e1001419. doi:10.1371/journal.pmed.1001419

Booth, A., Clarke, M., Dooley, G., Ghersi, D., Moher, D., Petticrew, M., \& Stewart, L. (2012). The nuts and bolts of PROSPERO: an international prospective register of systematic reviews. Syst Rev, 1, 2. doi:10.1186/2046-4053-1-2

Booth, A., Clarke, M., Ghersi, D., Moher, D., Petticrew, M., \& Stewart, L. (2011). An international registry of systematic-review protocols. Lancet, 377(9760), 108-109. doi:10.1016/s0140-6736(10)60903-8

Bossuyt, P. M., Reitsma, J. B., Bruns, D. E., Gatsonis, C. A., Glasziou, P. P., Irwig, L., . . Cohen, J. F. (2015). STARD 2015: an updated list of essential items for reporting diagnostic accuracy studies. Bmj, 351, h5527. doi:10.1136/bmj.h5527

Calvert, M., Blazeby, J., Altman, D. G., Revicki, D. A., Moher, D., \& Brundage, M. D. (2013). Reporting of patient-reported outcomes in randomized trials: the CONSORT PRO extension. Jama, 309(8), 814-822. doi:10.1001/jama.2013.879

Campbell, M. K., Piaggio, G., Elbourne, D. R., \& Altman, D. G. (2012). Consort 2010 statement: extension to cluster randomised trials. Bmj, 345, e5661. doi:10.1136/bmj.e5661

Chalmers, I., Bracken, M. B., Djulbegovic, B., Garattini, S., Grant, J., Gulmezoglu, A. M., . . . 
Oliver, S. (2014). How to increase value and reduce waste when research priorities are set. Lancet, 383(9912), 156-165. doi:10.1016/s0140-6736(13)62229-1

Chalmers, I., \& Glasziou, P. (2009). Avoidable waste in the production and reporting of research evidence. Lancet, 374(9683), 86-89. doi:10.1016/s0140-6736(09)60329-9

Chan, A. W., Song, F., Vickers, A., Jefferson, T., Dickersin, K., Gotzsche, P. C., ... van der Worp, H. B. (2014). Increasing value and reducing waste: addressing inaccessible research. Lancet, 383(9913), 257-266. doi:10.1016/s0140-6736(13)62296-5

Chan, A. W., Tetzlaff, J. M., Altman, D. G., Laupacis, A., Gotzsche, P. C., Krleza-Jeric, K., . . . Moher, D. (2013). SPIRIT 2013 statement: defining standard protocol items for clinical trials. Ann Intern Med, 158(3), 200-207. doi:10.7326/0003-4819-158-3-201302050-00583

Clarke, M., \& Chalmers, I. (1998). Discussion sections in reports of controlled trials published in general medical journals: islands in search of continents? Jama, 280(3), 280-282.

Clarke, M., Hopewell, S., \& Chalmers, I. (2007). Reports of clinical trials should begin and end with up-to-date systematic reviews of other relevant evidence: a status report. $J$ $R$ Soc Med, 100(4), 187-190. doi:10.1177/014107680710011415

Clauson, K. A., Veronin, M. A., Khanfar, N. M., \& Lou, J. Q. (2008). Open-access publishing for pharmacy-focused journals. Am J Health Syst Pharm, 65(16), 1539-1544. doi:10.2146/ajhp070625

Council, M. R. (2016). Data sharing policy;. https://www.mrc.ac.uk/documents/pdf/ mrc-data-sharing-policy/. [accessed 2019 Jun 29].

Davies, S. (2012). The importance of PROSPERO to the National Institute for Health Research. Syst Rev, 1, 5. doi:10.1186/2046-4053-1-5

De Angelis, C., Drazen, J. M., Frizelle, F. A., Haug, C., Hoey, J., Horton, R., . . . Van Der Weyden, M. B. (2004). Clinical trial registration: a statement from the International Committee of Medical Journal Editors. Lancet, 364(9438), 911-912. doi:10.1016/s0140-6736(04)17034-7

Des Jarlais, D. C., Lyles, C., \& Crepaz, N. (2004). Improving the reporting quality of nonrandomized evaluations of behavioral and public health interventions: the TREND statement. Am J Public Health, 94(3), 361-366. doi:10.2105/ajph.94.3.361

Egger, M., \& Smith, G. D. (1997). Meta-Analysis. Potentials and promise. Bmj, 315(7119), 1371-1374. doi:10.1136/bmj.315.7119.1371

Faggion, C. M. (2011). Policies of dental journals for reporting and monitoring authorship and contributorship. Br Dent J, 211(5), 223-227. doi:10.1038/sj.bdj.2011.721

Fournier, J. C., DeRubeis, R. J., Hollon, S. D., Dimidjian, S., Amsterdam, J. D., Shelton, R. C., \& Fawcett, J. (2010). Antidepressant drug effects and depression severity: a patient-level meta-analysis. Jama, 303(1), 47-53. doi:10.1001/jama.2009.1943

Gagnier, J. J., Kienle, G., Altman, D. G., Moher, D., Sox, H., \& Riley, D. (2013). The CARE Guidelines: Consensus-based Clinical Case Reporting Guideline Development. Glob Adv Health Med, 2(5), 38-43. doi:10.7453/gahmj.2013.008

Gallo, V., Egger, M., McCormack, V., Farmer, P. B., Ioannidis, J. P., Kirsch-Volders, M., . . . Vineis, P. (2011). STrengthening the Reporting of OBservational studies in Epidemiology--Molecular Epidemiology (STROBE-ME): an extension of the STROBE Statement. PLoS Med, 8(10), e1001117. doi:10.1371/journal.pmed.1001117

Giglia, E. (2010). Open access to scientific research: where are we and where are we going? 
Facts and figures on the occasion of the 2010 Open Access Week (October 18-24). Eur J Phys Rehabil Med, 46(3), 461-469.

Glasziou, P. (2014). The role of open access in reducing waste in medical research. PLoS Med, 11(5), e1001651. doi:10.1371/journal.pmed.1001651

Glasziou, P., Altman, D. G., Bossuyt, P., Boutron, I., Clarke, M., Julious, S., ... Wager, E. (2014). Reducing waste from incomplete or unusable reports of biomedical research. Lancet, 383(9913), 267-276. doi:10.1016/s0140-6736(13)62228-x

Glasziou P., C. I. (2015). How systematic review can reduce waste in research. http://blogs.bmj.com/bmj/2015/10/29/howsystematic-reviews-can-reduce-waste-inr esearch/(accessed Dec 20, 2018).

Gotzsche, P. C. (1987). Reference bias in reports of drug trials. Br Med J (Clin Res Ed), 295(6599), 654-656.

Groves, T. (2010). BMJ policy on data sharing. Bmj, 340, c564. doi:10.1136/bmj.c564

Habre, C., Tramer, M. R., Popping, D. M., \& Elia, N. (2014). Ability of a meta-analysis to prevent redundant research: systematic review of studies on pain from propofol injection. Bmj, 348, g5219. doi:10.1136/bmj.g5219

Health., D. o. (2001). Publications Policy And Guidance. http://webarchive.nationalarchives.gov.uk/+/www.dh.gov.uk/en/Publicationsandstat istics/, 4008777 (accessed May, 2019).

Hopewel, S., Clarke, M., Moher, D., Wager, E., Middleton, P., Altman, D. G., . . . The, C. G. (2008). [CONSORT for reporting randomized controlled trials in journal and conference abstracts: explanation and elaboration]. Zhong Xi Yi Jie He Xue Bao, 6(3), 221-232. doi:10.3736/jcim20080301

Hopewell, S., Ravaud, P., Baron, G., \& Boutron, I. (2012). Effect of editors' implementation of CONSORT guidelines on the reporting of abstracts in high impact medical journals: interrupted time series analysis. Bmj, 344, e4178. doi:10.1136/bmj.e4178

Hua, F., Shen, C., Walsh, T., Glenny, A. M., \& Worthington, H. (2017). Open Access: Concepts, findings, and recommendations for stakeholders in dentistry. J Dent, 64, 13-22. doi:10.1016/j.jdent.2017.06.012

Hua, F., Walsh, T., Glenny, A. M., \& Worthington, H. (2016). Surveys on Reporting Guideline Usage in Dental Journals. J Dent Res, 95(11), 1207-1213. doi:10.1177/0022034516657803

Hutton, B., Salanti, G., Caldwell, D. M., Chaimani, A., Schmid, C. H., Cameron, C., ... Moher, D. (2015). The PRISMA extension statement for reporting of systematic reviews incorporating network meta-analyses of health care interventions: checklist and explanations. Ann Intern Med, 162(11), 777-784. doi:10.7326/m14-2385

ICMJE. (2018). Recommendations for the conduct, reporting, editing, and publication of scholarly work in medical journals. Available at: http://www.icmje.org. Accessed December, 2018.

Ioannidis, J. P. (2008). Perfect study, poor evidence: interpretation of biases preceding study design. Semin Hematol, 45(3), 160-166. doi:10.1053/j.seminhematol.2008.04.010

Ioannidis, J. P. (2014). How to make more published research true. PLoS Med, 11(10), e1001747. doi:10.1371/journal.pmed.1001747

Ioannidis, J. P., Evans, S. J., Gotzsche, P. C., O'Neill, R. T., Altman, D. G., Schulz, K., \& Moher, D. (2004). Better reporting of harms in randomized trials: an extension of the 
CONSORT statement. Ann Intern Med, 141(10), 781-788. doi:10.7326/0003-4819-141-10-200411160-00009

Ioannidis, J. P., Greenland, S., Hlatky, M. A., Khoury, M. J., Macleod, M. R., Moher, D., . . . Tibshirani, R. (2014). Increasing value and reducing waste in research design, conduct, and analysis. Lancet, 383(9912), 166-175. doi:10.1016/s0140-6736(13)62227-8

Joseph, H. (2013). The open access movement grows up: taking stock of a revolution. PLoS Biol, 11(10), e1001686. doi:10.1371/journal.pbio.1001686

Kilkenny, C., Browne, W. J., Cuthill, I. C., Emerson, M., \& Altman, D. G. (2010). Improving bioscience research reporting: The ARRIVE guidelines for reporting animal research. J Pharmacol Pharmacother, 1(2), 94-99. doi:10.4103/0976-500x.72351

Kleinert, S., Benham, L., Collingridge, D., Summerskill, W., \& Horton, R. (2014). Further emphasis on research in context. Lancet, 384(9961), 2176-2177. doi:10.1016/s0140-6736(14)62047-x

Knuppel, H., Metz, C., Meerpohl, J. J., \& Strech, D. (2013). How psychiatry journals support the unbiased translation of clinical research. A cross-sectional study of editorial policies. PLoS One, 8(10), e75995. doi:10.1371/journal.pone.0075995

Kostkova, P., Brewer, H., de Lusignan, S., Fottrell, E., Goldacre, B., Hart, G., . . . Tooke, J. (2016). Who Owns the Data? Open Data for Healthcare. Front Public Health, 4, 7. doi:10.3389/fpubh.2016.00007

Kunath F, G. H., Rucker G, Engehausen D, Antes G, Wullich B, Meerpohl JJ. (2012). Do journals publishing in the field of urology endorse reporting guidelines? A survey of author instructions. Urol Int, 88(1):54-59.

Kurata, K., Morioka, T., Yokoi, K., \& Matsubayashi, M. (2013). Remarkable growth of open access in the biomedical field: analysis of PubMed articles from 2006 to 2010. PLoS One, 8(5), e60925. doi:10.1371/journal.pone.0060925

Little, J., Higgins, J. P., Ioannidis, J. P., Moher, D., Gagnon, F., von Elm, E., . . Birkett, N. (2009). STrengthening the REporting of Genetic Association studies (STREGA)--an extension of the STROBE statement. Eur J Clin Invest, 39(4), 247-266. doi:10.1111/j.1365-2362.2009.02125.x

Livas, C., Pandis, N., \& Ren, Y. (2015). Time relevance, citation of reporting guidelines, and breadth of literature search in systematic reviews in orthodontics. Eur J Orthod, 37(2), 183-187. doi:10.1093/ejo/cju032

Lund, H., Juhl, C., \& Christensen, R. (2016). Systematic reviews and research waste. Lancet, 387(10014), 123-124. doi:10.1016/s0140-6736(15)01354-9

McInnes, M. D. F., Moher, D., Thombs, B. D., McGrath, T. A., Bossuyt, P. M., Clifford, T., . . . Willis, B. H. (2018). Preferred Reporting Items for a Systematic Review and Meta-analysis of Diagnostic Test Accuracy Studies: The PRISMA-DTA Statement. Jama, 319(4), 388-396. doi:10.1001/jama.2017.19163

Meerpohl, J. J., Wolff, R. F., Antes, G., \& von Elm, E. (2011). Are pediatric Open Access journals promoting good publication practice? An analysis of author instructions. BMC Pediatr, 11, 27. doi:10.1186/1471-2431-11-27

Meerpohl, J. J., Wolff, R. F., Niemeyer, C. M., Antes, G., \& von Elm, E. (2010). Editorial policies of pediatric journals: survey of instructions for authors. Arch Pediatr Adolesc Med, 164(3), 268-272. doi:10.1001/archpediatrics.2009.287

Moher, D., Glasziou, P., Chalmers, I., Nasser, M., Bossuyt, P. M., Korevaar, D. A., ... Boutron, I. 
(2016). Increasing value and reducing waste in biomedical research: who's listening? Lancet, 387(10027), 1573-1586. doi:10.1016/s0140-6736(15)00307-4

Moher, D., Hopewell, S., Schulz, K. F., Montori, V., Gotzsche, P. C., Devereaux, P. J., ... Altman, D. G. (2010). CONSORT 2010 Explanation and Elaboration: Updated guidelines for reporting parallel group randomised trials. J Clin Epidemiol, 63(8), e1-37. doi:10.1016/j.jclinepi.2010.03.004

Moher, D., Liberati, A., Tetzlaff, J., \& Altman, D. G. (2009). Preferred reporting items for systematic reviews and meta-analyses: the PRISMA statement. Bmj, 339, b2535. doi:10.1136/bmj.b2535

Moher, D., Shamseer, L., Clarke, M., Ghersi, D., Liberati, A., Petticrew, M., . . Stewart, L. A. (2015). Preferred reporting items for systematic review and meta-analysis protocols (PRISMA-P) 2015 statement. Syst Rev, 4, 1. doi:10.1186/2046-4053-4-1

Moorhead, L. L., Holzmeyer, C., Maggio, L. A., Steinberg, R. M., \& Willinsky, J. (2015). In an Age of Open Access to Research Policies: Physician and Public Health NGO Staff Research Use and Policy Awareness. PLoS One, 10(7), e0129708. doi:10.1371/journal.pone.0129708

Nature.com. Policy on availability of data, material and methods;. https://www.nature.com/authors/ policies/availability.html.), (accessed 2018 Dec. 29).

Pandis, N., Chung, B., Scherer, R. W., Elbourne, D., \& Altman, D. G. (2017). CONSORT 2010 statement: extension checklist for reporting within person randomised trials. $B m j$, 357, j2835. doi:10.1136/bmj.j2835

Pandis, N., Shamseer, L., Kokich, V. G., Fleming, P. S., \& Moher, D. (2014). Active implementation strategy of CONSORT adherence by a dental specialty journal improved randomized clinical trial reporting. J Clin Epidemiol, 67(9), 1044-1048. doi:10.1016/j.jclinepi.2014.04.001

Papageorgiou, S. N., \& Cobourne, M. T. (2018). Data sharing in orthodontic research. J Orthod, 45(1), 1-3. doi:10.1080/14653125.2018.1440792

Pham-Kanter, G., Zinner, D. E., \& Campbell, E. G. (2014). Codifying collegiality: recent developments in data sharing policy in the life sciences. PLoS One, 9(9), e108451. doi:10.1371/journal.pone.0108451

Piaggio, G., Elbourne, D. R., Pocock, S. J., Evans, S. J., \& Altman, D. G. (2012). Reporting of noninferiority and equivalence randomized trials: extension of the CONSORT 2010 statement. Jama, 308(24), 2594-2604. doi:10.1001/jama.2012.87802

Piwowar, H. A., \& Chapman, W. W. (2008). Identifying data sharing in biomedical literature. AMIA Annu Symp Proc, 596-600.

Robinson, K. A., \& Goodman, S. N. (2011). A systematic examination of the citation of prior research in reports of randomized, controlled trials. Ann Intern Med, 154(1), 50-55. doi:10.7326/0003-4819-154-1-201101040-00007

Sawin, V. I., \& Robinson, K. A. (2016). Biased and inadequate citation of prior research in reports of cardiovascular trials is a continuing source of waste in research. J Clin Epidemiol, 69, 174-178. doi:10.1016/j.jclinepi.2015.03.026

Simera, I., Moher, D., Hirst, A., Hoey, J., Schulz, K. F., \& Altman, D. G. (2010). Transparent and accurate reporting increases reliability, utility, and impact of your research: reporting guidelines and the EQUATOR Network. BMC Med, 8, 24. doi:10.1186/1741-7015-8-24 
Smail-Faugeron, V., Fron-Chabouis, H., \& Durieux, P. (2015). Clinical trial registration in oral health journals. $J$ Dent Res, $94(3$ Suppl), 8s-13s. doi:10.1177/0022034514552492

Stroup, D. F., Berlin, J. A., Morton, S. C., Olkin, I., Williamson, G. D., Rennie, D., .. Thacker, S. B. (2000). Meta-analysis of observational studies in epidemiology: a proposal for reporting. Meta-analysis Of Observational Studies in Epidemiology (MOOSE) group. Jama, 283(15), 2008-2012. doi:10.1001/jama.283.15.2008

Tong, A., Sainsbury, P., \& Craig, J. (2007). Consolidated criteria for reporting qualitative research (COREQ): a 32-item checklist for interviews and focus groups. Int J Qual Health Care, 19(6), 349-357. doi:10.1093/intqhc/mzm042

Turner, L., Shamseer, L., Altman, D. G., Weeks, L., Peters, J., Kober, T., ... Moher, D. (2012). Consolidated standards of reporting trials (CONSORT) and the completeness of reporting of randomised controlled trials (RCTs) published in medical journals. Cochrane Database Syst Rev, 11, Mr000030. doi:10.1002/14651858.MR000030.pub2

von Elm, E., Altman, D. G., Egger, M., Pocock, S. J., Gotzsche, P. C., \& Vandenbroucke, J. P. (2007). Strengthening the Reporting of Observational Studies in Epidemiology (STROBE) statement: guidelines for reporting observational studies. Bmj, 335(7624), 806-808. doi:10.1136/bmj.39335.541782.AD

Wager, E., \& Williams, P. (2013). "Hardly worth the effort"? Medical journals' policies and their editors' and publishers' views on trial registration and publication bias: quantitative and qualitative study. $B m j, 347$, f5248. doi:10.1136/bmj.f5248

Wellcome Trust, D. s. (2016). Wellcome Trust Data sharing. http://www.wellcome.ac.uk/ About-us/Policy/Spotlight-issues/Data-sharing/(accessed 2019 April 28).

Zorzela, L., Loke, Y. K., Ioannidis, J. P., Golder, S., Santaguida, P., Altman, D. G., . . Vohra, S. (2016). PRISMA harms checklist: improving harms reporting in systematic reviews. $B m j$, 352, i157. doi:10.1136/bmj.i157 


\section{Acknowledgements}

This work was supported by the China Postdoctoral Science Foundation [grant number 2018M630884]; and the Wuhan Young and Middle-aged Medical Talents Training Program (No. [2019]87) to FH. The funding sources were not involved in the study design, collection, analysis, and interpretation of data, preparation of the manuscript, or in the decision to publish.

\section{Declaration of Interest}

None 


\section{Tables}

Table 1. Key reporting guidelines (RGs) relevant to dental research.

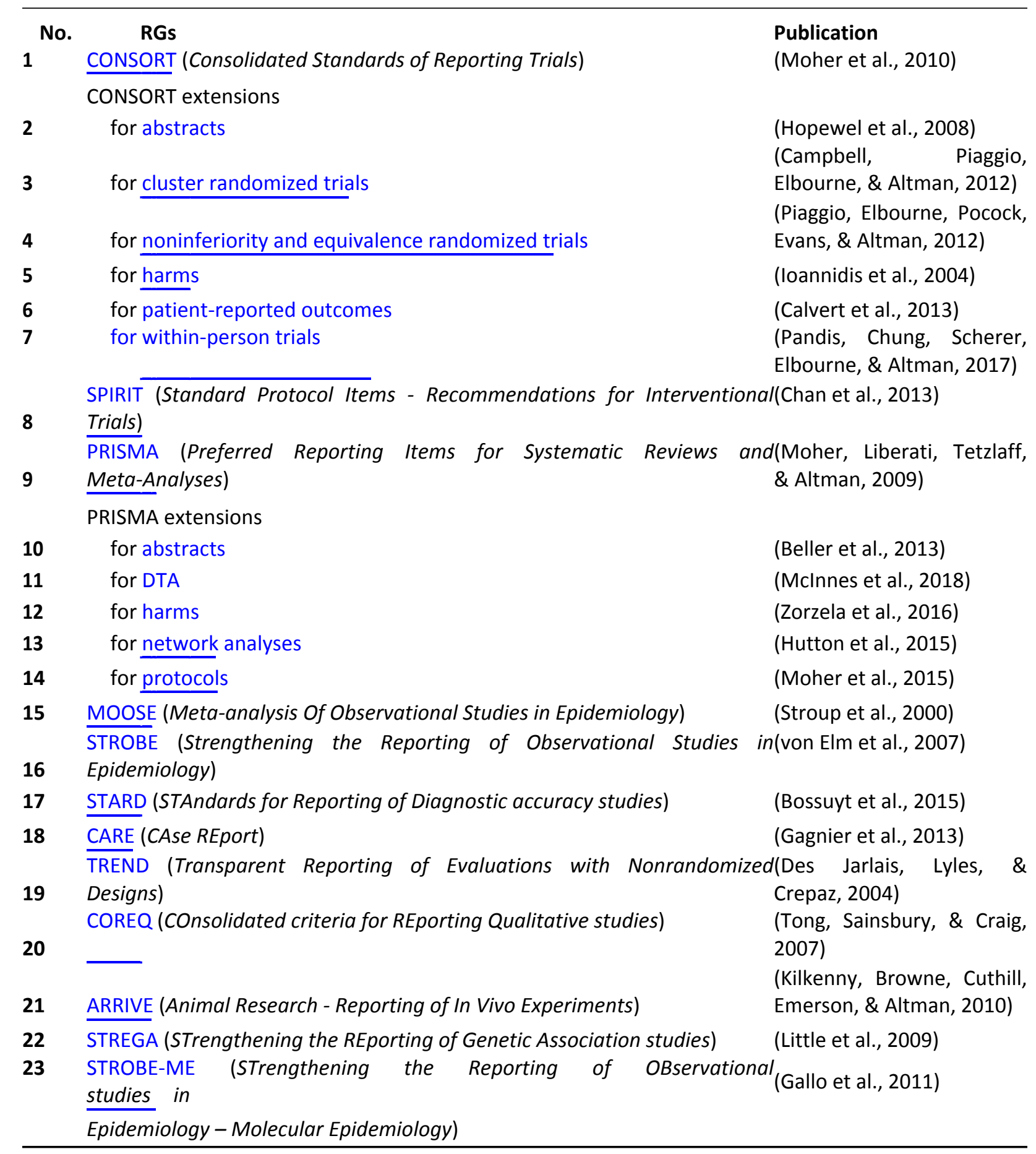

Table 2. Key International Committee of Medical Journal Editors (ICMJE) Recommendations. 


\section{Manuscript section}

Trial registration preparation

Manu Committee of Medical Journal Editors' revised 'Uniform Requirements for Manuscripts Submitted to Biomedical Journals.

Registration in a public trials registry is a condition for publication of clinical trials in accordance with International Committee of Medical Journal Editors recommendations. Trials must register at or before the onset of patient enrolment.

(ICMJE, 2018) 
Table 3. Journals included in this study and endorsement of EQUATOR Network, MIBBI and each of the 23 key RGs in their instructions to authors (as of November 2018).

\begin{tabular}{|c|c|c|c|c|c|c|c|c|c|c|c|c|c|c|c|c|c|c|c|c|c|c|c|}
\hline \multirow{2}{*}{$\begin{array}{l}\text { Journal } \\
\text { No. }\end{array}$} & \multirow{2}{*}{ Journal Title } & \multirow{2}{*}{$\mathrm{EN}^{\mathrm{a}}$} & \multirow{2}{*}{$\mathrm{MP}^{\mathrm{b}}$} & \multicolumn{20}{|c|}{ RG Noc } \\
\hline & & & & 1 & 2 & \begin{tabular}{l|l}
3 & 4 \\
\end{tabular} & \begin{tabular}{|l|l}
5 & 6 \\
\end{tabular} & \begin{tabular}{l|l}
6 & 7 \\
\end{tabular} & \begin{tabular}{l|l}
8 & 5 \\
\end{tabular} & \begin{tabular}{l|l}
9 & 10 \\
\end{tabular} & 11 & 12 & 13 & 14 & 15 & 16 & 17 & 18 & 19 & 20 & 21 & 22 & 23 \\
\hline 1 & Acta Odontol Latinoam & & & & & & & & & & & & & & & & & & & & & & \\
\hline 2 & Acta Odontol Scand & & & & & & & & & & & & & & & & & & & & & & \\
\hline 3 & Am J Dent & & & $\alpha$ & & & & & & & & & & & & & & & & & & & \\
\hline 4 & $\begin{array}{l}\text { Am J Orthod Dentofacial } \\
\text { Orthop }\end{array}$ & & & $\gamma$ & $\alpha$ & $\alpha \alpha$ & & & & $\gamma$ & & & & & & & & & & & $\alpha$ & & \\
\hline 5 & Anesth Prog & & & & & & & & & & & & & & & & & $\alpha$ & & & & & \\
\hline 6 & Angle Orthod & & & & & & & & & $\alpha$ & & & & & & & & & & & & & \\
\hline 7 & Arch Oral Biol & & & & & & & & & & & & & & & & & & & & $\alpha$ & & \\
\hline 8 & Aust Dent J & $\checkmark$ & & $\alpha$ & & & & & & & & & & & $\alpha$ & $\alpha$ & $\alpha$ & & & & & & \\
\hline 9 & Aust Endod J & $\checkmark$ & & $\alpha$ & & & & & & & & & & & $\alpha$ & $\alpha$ & $\alpha$ & & & & & & \\
\hline 10 & Aust Orthod J & & & & & & & & & & & & & & & & & & & & & & \\
\hline 11 & BMC Oral Health & $\checkmark$ & & $\alpha$ & a & & & & y & $\alpha$ & & & & $\alpha$ & & $\alpha$ & $\alpha$ & $\gamma$ & & $\alpha$ & $\alpha$ & & \\
\hline 12 & Br Dent J & & & $\beta$ & & & & & & $\beta$ & & & & & & & & & & & $\beta$ & & \\
\hline 13 & Br J Oral Maxillofac Surg & & & $\gamma$ & & & & & & & & & & & & & & & & & $\alpha$ & & \\
\hline 14 & Braz Dent J & & & & & & & & & & & & & & & & & & & & & & \\
\hline 15 & Braz Oral Res & & & $\beta$ & & & & & & $\beta$ & & & & & & y & & & & & & & \\
\hline 16 & Bull Tokyo Dent Coll & & & $\alpha$ & & & & & & & & & & & & & & & & & & & \\
\hline 17 & Caries Res & $\checkmark$ & & & & & & & & $\alpha$ & & & & & & & & & & & & & \\
\hline 18 & Chin J Dent Res & & & & & & & & & & & & & & & & & & & & & & \\
\hline 19 & Cleft Palate Craniofac J & $\checkmark$ & & $\gamma$ & & & & & & v & & & & & & & & & & & & & \\
\hline 20 & $\begin{array}{l}\text { Clin Implant Dent Relat } \\
\text { Res }\end{array}$ & & & v & & & & & & & & & & & & & & & & & & & \\
\hline 21 & Clin Oral Implants Res & $\checkmark$ & & v & & & & & & $\alpha$ & & & & & & $\gamma$ & & & & & r & & \\
\hline 22 & Clin Oral Investig & & & & & & & & & & & & & & & & & & & & & & \\
\hline 23 & Community Dent Health & & & $\alpha$ & & & & & & & & & & & & $\alpha$ & & & & & & & \\
\hline 24 & $\begin{array}{l}\text { Community Dent Oral } \\
\text { Epidemiol }\end{array}$ & $\checkmark$ & & $\gamma$ & & & & & & & & & & & $\alpha$ & $\alpha$ & & & & & & & \\
\hline 25 & Cranio & & & & & & & & & & & & & & & & & & & & & & \\
\hline 26 & Dent Mater & & & & & & & & & & & & & & & & & & & & $\alpha$ & & \\
\hline 27 & Dent Mater J & & & & & & & & & & & & & & & & & & & & & & \\
\hline
\end{tabular}


Eur Arch Paediatr Dent

Eur J Dent Educ

Eur J Oral Implantol

Eur J Oral Sci

Eur J Orthod

Eur J Paediatr Dent

Eur J Prosthodont Restor

Dent

Gen Dent

Gerodontology

Head Face Med

Implant Dent

Indian J Dent Res

Int Dent J

Int Endod J

Int J Comput Dent

Int J Dent Hyg

Int J Esthet Dent

Oral Maxillofac Implants

Int J Oral Maxillofac Surg 
J Clin Periodontol

Contemp Dent Pract

J Craniomaxillofac Surg

Jent

J Dent Child (Chic)

J Dent Educ

J Dent Res

J Dent Sci

J Endod

J Esthet Restor Dent

J Evid Based Dent Pract

J Indian Soc Pedod Prev

Dent

J Investig Clin Dent

J Oral Facial Pain

Headache

J Oral Implantol

J Oral Maxillofac Surg

J Oral Pathol Med

J Oral Rehabil

J Oral Sci

J Orofac Orthop

J Orthod

J Periodontal Implant Sci

J Periodontal Res

J Periodontol

J Prosthet Dent

J Prosthodont

J Prosthodont Res

J Public Health Dent

Stomato

Oral Maxillofac Surg

Korean J Orthod

91 Med Oral Patol Oral Cir

Bucal 


\section{Odontology \\ Oper Dent}

Oral Dis

Oral Health Prev Dent

Oral Maxillofac Surg

Oral Maxillofac Surg Clin

North Am

Oral Oncology

Oral Radiol

\section{Oral Surg Oral Med Oral}

orth craniofac Res

Pediatr Dent

Periodontol 2000

Prog Orthod

Quintessence Int

Singapore Dent J

Spec Care Dentist

Stomatologija

$\sqrt{ }$ : The corresponding online RG library mentioned; $\alpha$ : Adherence to RG recommended but not required; $\beta$ : Adherence to RG required but submission of relevant checklist/flow diagrams not required; $\gamma$ : Both adherence to RG and submission of relevant checklist/flow diagrams required.

${ }^{a}$ Mentioning of the EQUATOR Network.

${ }^{\mathbf{b}}$ Mentioning of the MIBBI Portal.

For each RG number, see the corresponding RG title in Table 1 
Table 4. Characteristics of included journals.

\begin{tabular}{|c|c|c|c|}
\hline Characteristic & Category & $\mathbf{N}$ & $\%$ \\
\hline \multirow[t]{2}{*}{ Type } & General dental journal & 33 & 30.2 \\
\hline & Specialty dental journal & 76 & 69.7 \\
\hline \multirow[t]{11}{*}{ Subject } & Dentistry & 33 & 30.3 \\
\hline & Dental Public Health & 4 & 3.7 \\
\hline & Endodontics & 5 & 4.6 \\
\hline & Oral and Maxillofacial Surgery & 10 & 9.1 \\
\hline & Orthodontics & 10 & 9.1 \\
\hline & Paediatric Dentistry & 7 & 6.4 \\
\hline & Periodontics & 7 & 6.4 \\
\hline & Prosthodontics & 9 & 8.3 \\
\hline & Restorative Dentistry & 4 & 3.7 \\
\hline & Dental Materials & 3 & 2.8 \\
\hline & Other & 17 & 15.6 \\
\hline \multirow[t]{2}{*}{ SCIE Indexed } & Yes & 86 & 78.9 \\
\hline & No & 23 & 21.1 \\
\hline \multirow[t]{5}{*}{ Impact Factor } & Unavailable & 24 & 22.1 \\
\hline & $\leq 1$ & 11 & 10 \\
\hline & $1-2$ & 45 & 41.3 \\
\hline & $2-3$ & 19 & 17.4 \\
\hline & $\geq 3$ & 10 & 9.1 \\
\hline \multirow[t]{2}{*}{ Open Access } & Yes & 78 & 71.6 \\
\hline & No & 31 & 28.4 \\
\hline Total & & 109 & 100 \\
\hline
\end{tabular}

$\mathrm{N}$ : number of journals. 
Table 5. Endorsement of Each Specific Reporting Guideline in Instructions for Authors ( $N=109$ Journals).

\begin{tabular}{|c|c|c|c|c|c|c|c|}
\hline \multirow[b]{2}{*}{ Reporting Guideline } & \multicolumn{2}{|c|}{ Mentioned, n (\%) } & \multicolumn{3}{|c|}{ Level of Endorsement, n (\%) } & \multicolumn{2}{|c|}{ Reference, $\mathrm{n}(\%)^{\mathrm{a}}$} \\
\hline & No & Yes & Recommended & Required & Submission ${ }^{b}$ & $\begin{array}{l}\text { Reference } \\
\text { Given }\end{array}$ & $\begin{array}{l}\text { Website URL } \\
\text { Given }\end{array}$ \\
\hline CONSORT & $56(51.4)$ & $53(49.6)$ & $15(13.7)$ & $7(6.4)$ & $31(28.5)$ & $33(62.3)$ & $19(35.8)$ \\
\hline \multicolumn{8}{|l|}{ CONSORT extensions } \\
\hline For abstract & $105(96.3)$ & $4(3.7)$ & $4(3,7)$ & $0(0.0)$ & $0(0.0)$ & $0(0.0)$ & $1(25.0)$ \\
\hline For CRT & $107(98.2)$ & $2(1.8)$ & $2(1.8)$ & $0(0.0)$ & $0(0.0)$ & $0(00.0)$ & $0(00.0)$ \\
\hline For noninferiority trials & $107(98.2)$ & $2(1.8)$ & $1(0.9)$ & $0(0.0)$ & $0(0.0)$ & $0(00.0)$ & $0(00.0)$ \\
\hline For harms & $109(100)$ & $0(0.0)$ & $0(0.0)$ & $0(0.0)$ & $0(0.0)$ & $0(0.0)$ & $0(0.0)$ \\
\hline For PRO & $109(100.0)$ & $0(0.0)$ & $0(0.0)$ & $0(0.0)$ & $0(0.0)$ & $0(0.0)$ & $0(0.0)$ \\
\hline For within-person trials & $109(100.0)$ & $0(0.0)$ & $0(0.0)$ & $0(0.0)$ & $0(0.0)$ & $0(0.0)$ & $0(0.0)$ \\
\hline SPIRIT & $103(94.5)$ & $6(5.5)$ & $4(3.7)$ & $0(0.0)$ & $2(1.8)$ & $0(0.0)$ & $5(83.3)$ \\
\hline PRISMA & $79(72.5)$ & $30(27.5)$ & $15(13.8)$ & $8(7.4)$ & $7(6.4)$ & $11(36.7)$ & $14(46.7)$ \\
\hline \multicolumn{8}{|l|}{ PRISMA extensions } \\
\hline For abstract & $109(100)$ & $(0.0) 0$ & $(0.0) 0$ & $0(0.0)$ & $0(0.0)$ & $0(0.0)$ & $0(0.0)$ \\
\hline DTA & $109(100)$ & $(0.0) 0$ & $(0.0) 0$ & $(0.0) 0$ & $(0.0) 0$ & $0(0.0)$ & $0(0.0)$ \\
\hline harm & $109(100)$ & $(0.0) 0$ & $(0.0) 0$ & $(0.0) 0$ & $(0.0) 0$ & $0(0.0)$ & $0(0.0)$ \\
\hline Network analysis & $109(100)$ & $(0.0) 0$ & $(0.0) 0$ & $(0.0) 0$ & $(0.0) 0$ & $0(0.0)$ & $0(0.0)$ \\
\hline For protocol & $105(96.3)$ & $4(3.7)$ & $4(3.7)$ & $(0.0) 0$ & $(0.0) 0$ & $0(0.0)$ & $3(75.0)$ \\
\hline MOOSE & $105(96.3)$ & $4(3.7)$ & $3(2.8)$ & $0(0.0)$ & $1(0.9)$ & $0(0.0)$ & $1(25.0)$ \\
\hline STROBE & $87(79.8)$ & $22(20.2)$ & $14(12.8)$ & $2(1.8)$ & $6(5.5)$ & $9(41.0)$ & $8(36.4)$ \\
\hline STARD & 98 (89.9) & $11(10.1)$ & $8(7.3)$ & $0(0.0)$ & $3(2.8)$ & $2(18.2)$ & $6(54.5)$ \\
\hline CARE & $103(94.5)$ & $6(5.5)$ & $3(2.7)$ & $0(0.0)$ & $3(2.7)$ & $0(00.0)$ & $5(83.3)$ \\
\hline TREND & $108(99.1)$ & $1(0.9)$ & $1(0.9)$ & $0(0.0)$ & $0(0.0)$ & $0(00.0)$ & $0(00.0)$ \\
\hline COREQ & $104(95.4)$ & $5(4.6)$ & $4(3.7)$ & $0(00.0)$ & $1(0.9)$ & $0(00.0)$ & $4(80.0)$ \\
\hline ARRIVE & $83(76.1)$ & $26(23.9)$ & $20(18.3)$ & $2(1.8)$ & $4(3.7)$ & $4(16.0)$ & $19(73.0)$ \\
\hline STREGA & $109(100.0)$ & $0(0.0)$ & $0(0.0)$ & $0(0.0)$ & $0(0.0)$ & $0(0.0)$ & $0(0.0)$ \\
\hline STROBE-ME & $109(100.0)$ & $0(0.0)$ & $0(0.0)$ & $0(0.0)$ & $0(0.0)$ & $0(0.0)$ & $0(0.0)$ \\
\hline
\end{tabular}

ARRIVE, Animal Research: Reporting of In Vivo Experiments; CARE, Case Report; CONSORT, Consolidated Standards of Reporting Trials; COREQ, Consolidated Criteria for Reporting Qualitative Studies; CRT, cluster randomized trials; MOOSE, Meta-analysis of Observational Studies in Epidemiology; PRISMA, Preferred Reporting Items for Systematic Reviews and Meta-analyses; DTA, Preferred Reporting Items for a Systematic Review and Meta-analysis of Diagnostic Test Accuracy Studies ; PRO, patient-reported outcomes; STARD, Standards for Reporting of Diagnostic Accuracy Studies; STREGA, Strengthening the Reporting of Genetic Association Studies; STROBE, Strengthening the Reporting of Observational Studies in Epidemiology; STROBE-ME, Strengthening the Reporting of Observational Studies in Epidemiology-Molecular Epidemiology; TREND, Transparent Reporting of Evaluations with Nonrandomized Designs. ${ }^{a}$ The proportion among those mentioned the corresponding reporting guideline. ${ }^{b}$ Both adherence to the reporting guideline and submission of relevant checklists/flow diagrams required. 
Table 6. Mentioning of Each Policy in the Instructions to Authors ( $N=109$ Journals).

\begin{tabular}{|c|c|c|c|c|c|c|c|c|c|c|c|c|c|c|c|c|}
\hline \multirow{2}{*}{$\begin{array}{r}\text { Characteristic: } \\
\text { Category }\end{array}$} & \multirow[t]{2}{*}{ Total } & \multirow{2}{*}{\multicolumn{2}{|c|}{$\begin{array}{cc} & \text { Reporting } \\
n & \%\end{array}$}} & \multirow{2}{*}{$\begin{array}{l}\text { guideline } \\
P \text { Value }^{\mathrm{a}}\end{array}$} & \multicolumn{4}{|c|}{ Trial registration } & \multirow[b]{2}{*}{$\%$} & \multicolumn{2}{|l|}{ ICMJE } & \multicolumn{3}{|c|}{ OPEN ACCESS } & \multicolumn{2}{|c|}{ Data sharing } \\
\hline & & & & & $n$ & $\%$ & $P$ Value $^{\mathrm{a}}$ & $n$ & & $P$ Value & $n$ & $\%$ & $P$ Value $^{\mathrm{a}}$ & $n$ & $\%$ & $P$ Value ${ }^{\mathrm{a}}$ \\
\hline \multicolumn{17}{|l|}{ Dental journal } \\
\hline $\begin{array}{l}\text { General } \\
\text { Snecialty }\end{array}$ & 33 & 20 & 60.6 & 0.792 & 15 & 45.5 & 0.844 & 21 & 63.6 & 0.351 & 23 & 69.7 & 0.776 & 10 & 30.3 & 0.886 \\
\hline \multicolumn{17}{|l|}{ Subject } \\
\hline Dentistry & 33 & 20 & 60.6 & 0.082 & 15 & 45.5 & 0.235 & 21 & 63.6 & 0.331 & 23 & 69.7 & 0.341 & 10 & 30.3 & 0.223 \\
\hline $\begin{array}{l}\text { Dental public } \\
\text { health }\end{array}$ & 4 & 3 & 75.0 & & 2 & 50.0 & & 3 & 75.0 & & 2 & 50.0 & & 0 & 0.0 & \\
\hline Endodontics & 5 & 5 & 100.0 & & 2 & 40.0 & & 5 & 100.0 & & 5 & 100.0 & & 2 & 40.0 & \\
\hline $\begin{array}{l}\text { Oral and } \\
\text { maxillofacial } \\
\text { surgery }\end{array}$ & 10 & 7 & 70.0 & & 7 & 70.0 & & 9 & 90.0 & & 9 & 90.0 & & 7 & 70.0 & \\
\hline Orthodontics & 10 & 6 & 60.0 & & 4 & 40.0 & & 5 & 50.0 & & 7 & 70.0 & & 2 & 20.0 & \\
\hline Pediatric dentistry & 7 & 4 & 57.1 & & 1 & 14.3 & & 4 & 57.1 & & 3 & 42.9 & & 2 & 28.6 & \\
\hline Periodontics & 7 & 5 & 71.4 & & 5 & 71.4 & & 5 & 71.4 & & 6 & 85.7 & & 1 & 14.3 & \\
\hline Prosthodontics & 9 & 2 & 22.2 & & 2 & 22.2 & & 5 & 55.6 & & 5 & 55.6 & & 2 & 22.2 & \\
\hline $\begin{array}{l}\text { Restorative } \\
\text { dentistry }\end{array}$ & 4 & 0 & 0.0 & & 1 & 25.0 & & 2 & 50.0 & & 2 & 50.0 & & 0 & 0.0 & \\
\hline Dental materials & 3 & 1 & 33.3 & & 0 & 0.0 & & 1 & 33.3 & & 2 & 66.7 & & 1 & 33.3 & \\
\hline Other & 17 & 11 & 64.7 & & 9 & 52.9 & & 14 & 82.4 & & 14 & 82.4 & & 5 & 29.4 & \\
\hline \multicolumn{17}{|l|}{ SCIE indexed } \\
\hline Yes & 86 & 54 & 62.8 & 0.095 & 43 & 50.0 & 0.015 & 62 & 72.1 & 0.069 & 69 & 80.2 & $<0.001$ & 28 & 32.6 & 0.156 \\
\hline No & 23 & 10 & 43.5 & & 5 & 21.7 & & 12 & 52.2 & & 9 & 39.1 & & 4 & 17.4 & \\
\hline \multicolumn{17}{|l|}{ Impact factor } \\
\hline Unavailable & 24 & 11 & 45.8 & 0.026 & 6 & 25.0 & 0.007 & 13 & 54.2 & 0.109 & 10 & 41.7 & $<0.001$ & 5 & 20.8 & 0.275 \\
\hline$\leq 1$ & 11 & 4 & 36.4 & & 1 & 9.1 & & 5 & 45.5 & & 4 & 36.4 & & 1 & 9.1 & \\
\hline 1 to 2 & 45 & 25 & 55.6 & & 23 & 51.1 & & 33 & 73.3 & & 36 & 80.0 & & 14 & 31.1 & \\
\hline 2 to 3 & 19 & 16 & 84.2 & & 11 & 57.9 & & 16 & 84.2 & & 18 & 94.7 & & 8 & 42.1 & \\
\hline$\geq 3$ & 10 & 8 & 80.0 & & 7 & 70.0 & & 7 & 70.0 & & 10 & 100.0 & & 4 & 40.0 & \\
\hline \multicolumn{17}{|l|}{ Open access } \\
\hline Yes & 72 & 51 & 70.8 & $<0.001$ & 42 & 58.3 & $<0.001$ & 54 & 75.0 & 0.027 & & & & 32 & 44.4 & $<0.001$ \\
\hline \multirow{2}{*}{\multicolumn{17}{|c|}{ ICMJE mentioned }} \\
\hline & & & & & & & & & & & & & & & & \\
\hline Yes & 74 & 56 & 75.7 & $<0.001$ & 46 & 62.2 & $<0.001$ & & & & 59 & 79.7 & 0.006 & 27 & 36.5 & 0.017 \\
\hline No & 35 & 8 & 22.9 & & 2 & 5.7 & & & & & 19 & 54.3 & & 5 & 14.3 & \\
\hline Total & 109 & 64 & 58.7 & & 48 & 44.0 & & 74 & 67.9 & & 78 & 66.1 & & 32 & 29.4 & \\
\hline
\end{tabular}

ICMJE, International Committee of Medical Journal Editors. ${ }^{a}$ Chi-square tests. 
Table 7. Information regarding online reporting guideline libraries in instructions for authors $(n=109)$.

\begin{tabular}{|c|c|c|c|}
\hline Library & Category & $\mathbf{N}$ & $\%$ \\
\hline \multirow[t]{4}{*}{ EQUATOR Network } & Not mentioned & 92 & 84.4 \\
\hline & Mentioned & 17 & 15.6 \\
\hline & Reference given & 6 & $35.2^{\mathbf{a}}$ \\
\hline & Website URL given & 10 & $58.8^{\mathbf{a}}$ \\
\hline \multirow[t]{4}{*}{ MIBBI Portal } & Not mentioned & 106 & 97.2 \\
\hline & Mentioned & 3 & 2.8 \\
\hline & Reference given & 3 & $100.0^{\mathrm{a}}$ \\
\hline & Website URL given & 3 & $100.0^{\mathbf{a}}$ \\
\hline
\end{tabular}

Table 8. Trial registration

\begin{tabular}{llll}
\hline registration & Category & N & \% \\
\hline Trial registration & Not mentioned & 61 & 56.0 \\
& Mentioned & 48 & 44.0 \\
& Recommended & 16 & $33.3^{\mathrm{a}}$ \\
& Required & 32 & $66.7^{\mathrm{a}}$ \\
& & & \\
Systemic review & Not mentioned & 103 & 94.5 \\
& Mentioned & 6 & 5.5 \\
\hline
\end{tabular}

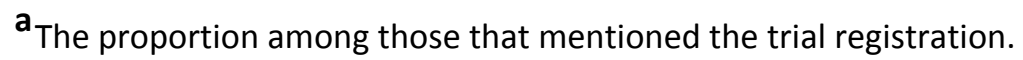

Table 9. Endorsement of in instructions for authors $(n=109)$

\begin{tabular}{lll}
\hline ICMJE Recommendation & $\mathbf{N}$ & $\%$ \\
\hline Not mentioned & 35 & 32.1 \\
Mentioned & 74 & 67.9 \\
Reference given & 43 & $58.1^{\mathrm{a}}$ \\
Website URL given & 15 & $20.3^{\mathrm{a}}$ \\
\hline
\end{tabular}




\begin{tabular}{lcc}
\hline Inappropriate title(URM) & 32 & $43.2^{\mathrm{a}}$ \\
Referred to its manuscript preparation section & 10 & $13.5^{\mathrm{a}}$ \\
Trial registration & 18 & 16.5 \\
\hline
\end{tabular}

ICMJE: International Committee of Medical Journal Editors.

$\mathrm{N}$ : number of journals.

URM: Uniform Requirements for Manuscripts submitted to biomedical journals.

a The proportion among those that mentioned the ICMJE Recommendations.

Table 10. Information regarding open access policy in instructions for authors ( $n=109)$.

\begin{tabular}{llll}
\hline Category & N & $\%$ \\
\hline Open access & Not mentioned & 31 & 28.4 \\
Mentioned & 78 & 71.6 \\
Direct OA & 12 & $15.4^{\mathrm{a}}$ \\
Hybrid OA & 64 & $82.0^{\mathrm{a}}$ \\
& & \\
Green only & 2 & $2.6^{\mathrm{a}}$ \\
\hline
\end{tabular}

${ }^{\mathbf{b}}$ The proportion among those that mentioned the open access policies.

Table 11. Information regarding data sharing policy in instructions for authors ( $n=109)$.

\begin{tabular}{|c|c|c|c|}
\hline & Category & $\mathbf{N}$ & $\%$ \\
\hline \multirow[t]{5}{*}{ Data sharing } & Not mentioned & 77 & 70.6 \\
\hline & Mentioned & 32 & 29.4 \\
\hline & Recommended & 30 & $93.8^{a}$ \\
\hline & Required & 2 & $6.2^{\mathrm{a}}$ \\
\hline & Reference given & 17 & $53.1^{a}$ \\
\hline \multirow[t]{3}{*}{ Data available statement } & Not mentioned & 87 & 79.8 \\
\hline & Mentioned & 22 & 20.2 \\
\hline & Reference given & 17 & $77.3^{a}$ \\
\hline
\end{tabular}



The proportion among those that mentioned the data sharing policy.

\section{Figure Legends}

Figure 1. Flow diagram for journal selection.

Figure 2. Proportion of mentioning for each editorial policy in the included instructions for authors ( $\mathrm{n}=109)$.

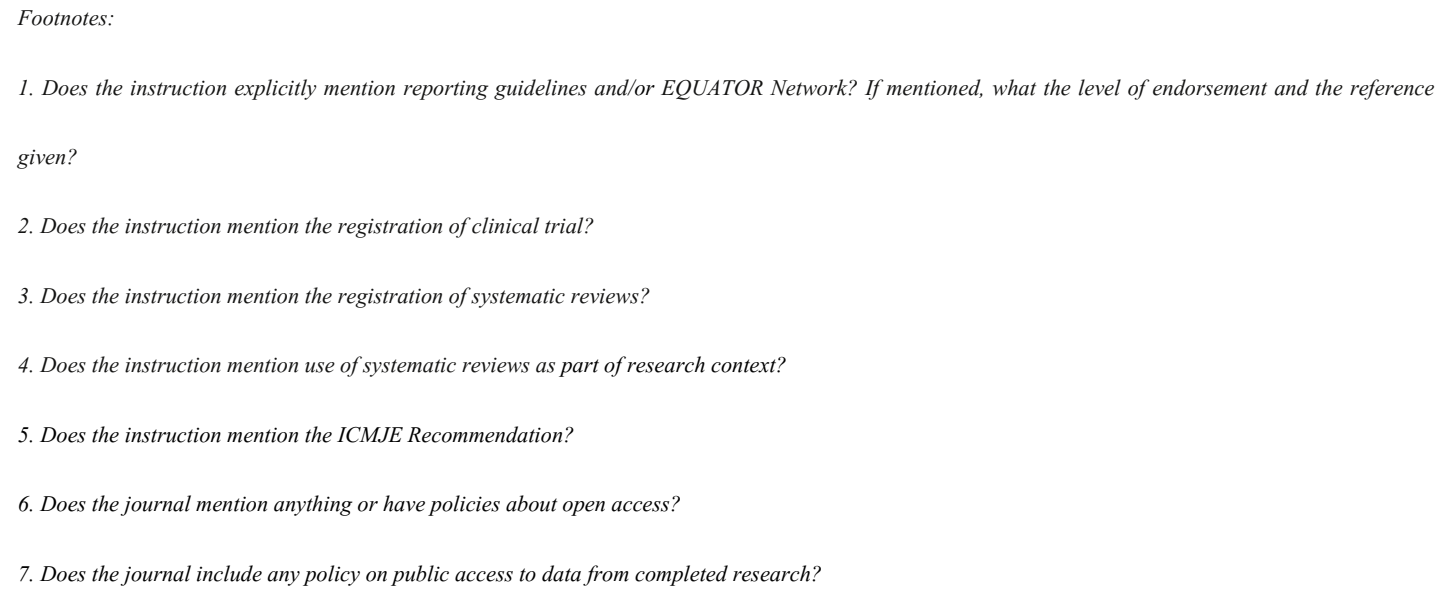


Figure 1. Flow diagram for journal selection.

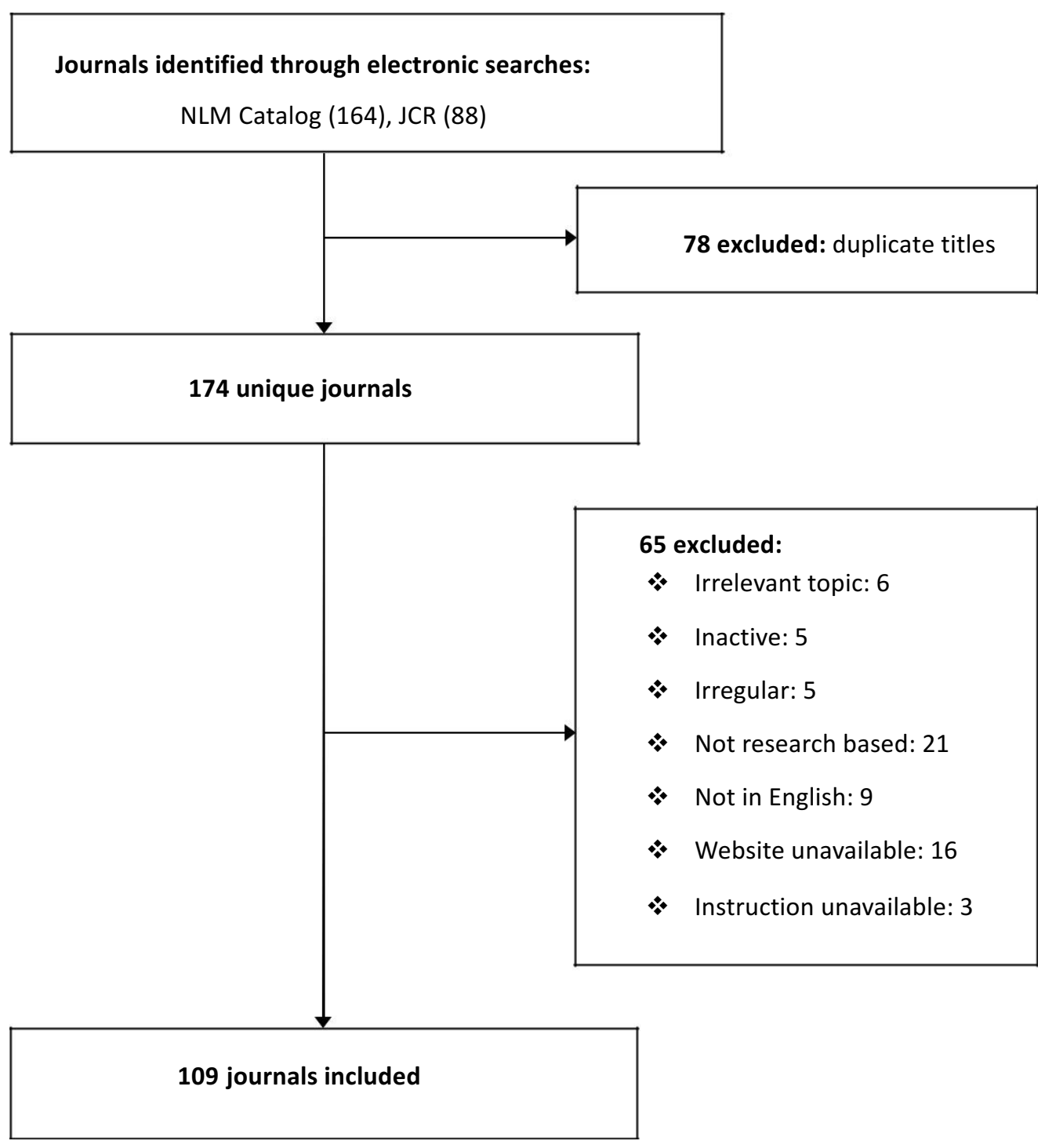


Figure 2. Proportion of mentioning for each editorial policy in the included instructions for authors $(n=109)$.

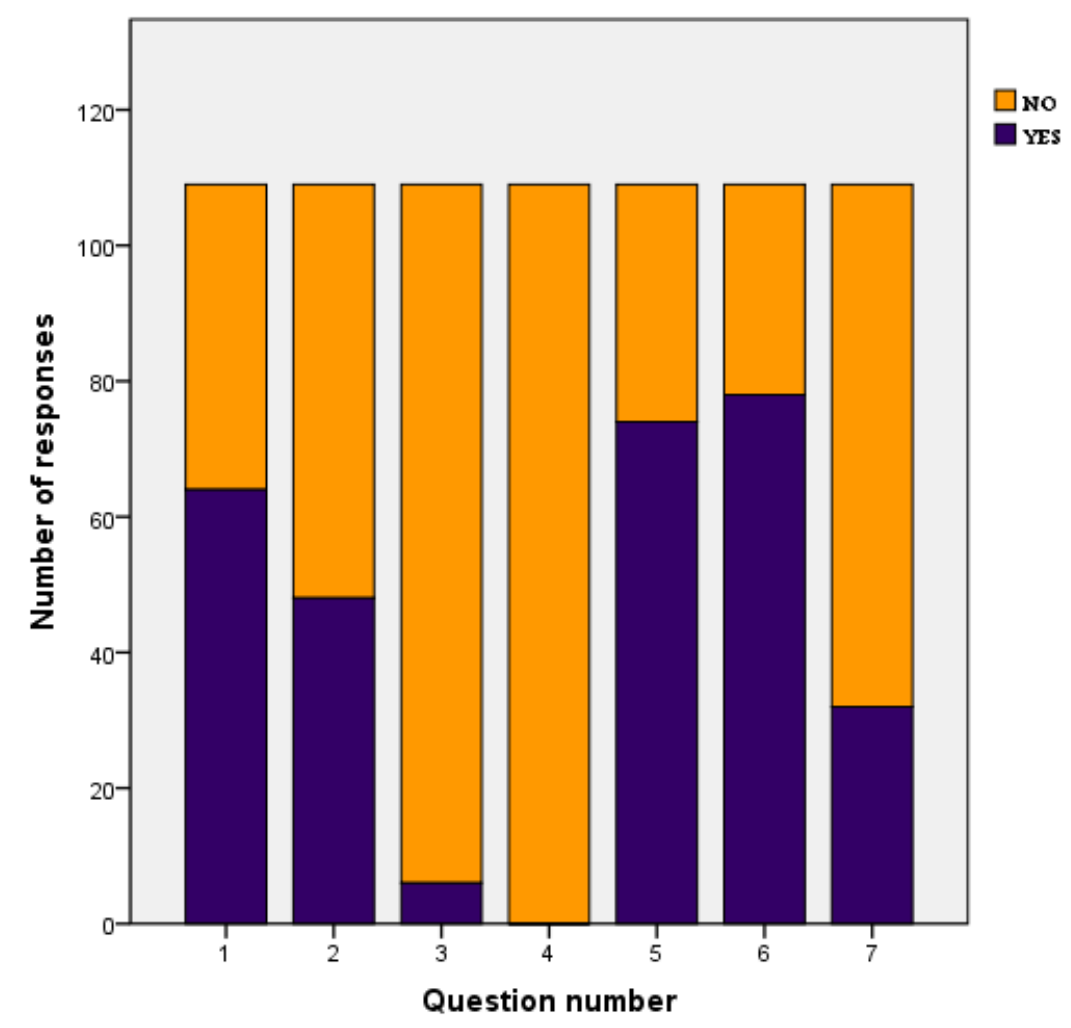

1. Does the instruction explicitly mention reporting guidelines and/or EQUATOR Network? If mentioned, what the level of endorsement and the reference given?

2. Does the instruction mention the registration of clinical trial?

3. Does the instruction mention the registration of systematic reviews?

4. Does the instruction mention use of systematic reviews as part of research context?

5. Does the instruction mention the ICMJE Recommendation?

6. Does the journal mention anything or have policies about open access?

7. Does the journal include any policy on public access to data from completed research? 
Figure 2. Proportion of mentioning for each editorial policy in the included instructions for authors $(n=109)$.

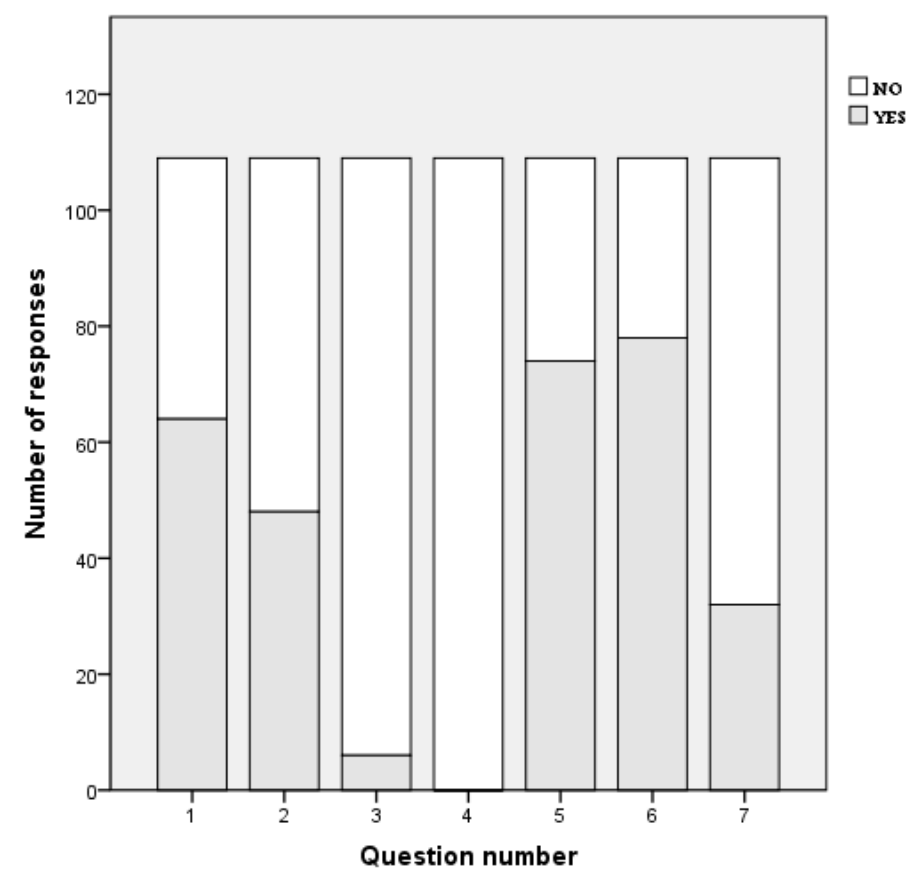

1. Does the instruction explicitly mention reporting guidelines and/or EQUATOR Network? If mentioned, what the level of endorsement and the reference given?

2. Does the instruction mention the registration of clinical trial?

3. Does the instruction mention the registration of systematic reviews?

4. Does the instruction mention use of systematic reviews as part of research context?

5. Does the instruction mention the ICMJE Recommendation?

6. Does the journal mention anything or have policies about open access?

7. Does the journal include any policy on public access to data from completed research? 